\title{
A PORTABLE VACUUM THERMOPILE
}

\author{
By W. W. Coblentz
}

\section{ABSTRACT}

A description is given of a portable vacuum thermopile of glass, in which the calcium evacuator is permanently attached to the container. The paper gives general directions for operating the device, as well as data on the thermopile, which is of bismuth silver.

Observations extending over a period of about seven years are given on the behavior of vacuum thermopiles in which the vacuum is maintained by means of calcium, which has the property of combining with gases when it is heated.

\section{CONTENTS}

Page

I. Introductory statement. $\ldots, \ldots, \ldots, \ldots, \ldots, \ldots, \ldots, \ldots, \ldots, \ldots, \quad 187$

2. Description of the thermopile $\ldots \ldots \ldots \ldots \ldots \ldots \ldots \ldots \ldots \ldots \ldots \ldots \ldots \ldots,{ }_{18} 8_{9}$

3. Description of the vacuum thermopile container................... I89

4. Concerning radiation sensitivity tests of vacuum radiometers........... IgI

\section{INTRODUCTORY STATEMENT}

The object of this paper is to describe a vacuum thermopile mounting which is rendered portable by attaching a calcium evacuator permanently to the radiometer container.

By this simple means one can maintain a vacuum without being obliged to keep the radiometer attached to a pump.

One of the chief complaints of workers in thermal radiometry is the uncertainty of the measurements caused by unsteadiness of atmospheric conditions. Radiometers are necessarily of small heat capacity and as a consequence are greatly affected by air currents. The loss of heat by convection is very large. The sensitivity of a modern thermopile-that is, its rise in temperature when exposed to radiation-is doubled and that of a thermocouple of fine $(0.01 \mathrm{~mm})$ wire is quadrupled by placing it in an evacuated receptacle. ${ }^{3}$

The container for a vacuum bolometer or thermopile differs from that of an evacuated, glass bulb, incandescent lamp in that it can not be thoroughly heated to expel the adsorbed water vapor and occluded gases. The radiometer container is usually provided

\footnotetext{
1 B. S. Bull., 11, pp. $x_{32}$ and $6 x_{3} ;$ 1984. $54164^{\circ}-21$
} 
with a fluorite or rock salt window which can not be heated without risk of breakage, and hence is attached with a cement that may give off vapors. Furthermore the radiometer receiver is covered with lampblack, etc., containing absorbed gases which slowly escape into an evacuated container.

As a result of these difficulties attempts to seal off the vacuum radiometer permanently from the evacuating device have not been successful. ${ }^{2}$ Consequently it is necessary to provide a vacuum pump or other means for removing the hydrocarbon vapors coming from the stopcock grease and the gases disengaged from the walls or leaking through the joints of the vacuum chamber.

In a previous paper ${ }^{3}$ a simple radiometric attachment was described for maintaining a vacuum by means of metallic calcium, which has the property of chemically combining with all atmospheric gases except argon. It is a simplification of the method used by Soddy, ${ }^{4}$ in that the calcium is contained in a quartz tube which is heated to a low red by either a Bunsen burner, an alcohol lamp, or electrically. The calcium, being covered with a thin coating of oxide, does not combine with the quartz container unless it is heated to a bright red color.

Portable vacuum thermopiles in which the vacuum is maintained by means of calcium have been in use by the writer for nearly seven years. One of the vacuum thermocouple containers (No. 7) used in stellar radiometry ${ }^{5}$ was provided with a new quartz tube and calcium on March 22, I 919. On January 19, 1921, there was found only a slight decrease in vacuum (total pressure perhaps $0.5 \mathrm{~mm}$ ). This was easily remedied by warming the quartz tube containing the calcium. Container No. 6 used in stellar radiometry was heated December 10, I 917 , for the first time after August, 1914 , and then again the second time on January I9, I92I-twice in seven years. This vacuum container, which begain to leak soon after it was finished, was easily repaired by applying a coat of shellac. However, as mentioned in the previous paper, sufficient air had entered to impart to the Geissler tube discharge the characteristic blue color of argon. In the most recent attempt to remove this residual gas (pressure less than I mm after standing three years) prolonged heating of the calcium evacuator had no effect in diminishing the argon.

\footnotetext{
2 Buchwald, Ann. der Phys. (4), 33, p. 928; $89 x 0$.

B. S. Bull., 11, p. 185 ; 1914.

"Soddy, Proc. Roy. Soc., 78, p. 429; 1907. Baly's Spectroscopy, new ed., p. 433. Magnesium is also reported to be good for "vacuum cleanup."

B. S. Bull., 11, p. 624, Fig. 3; 1914.
} 
Scientific Papers of the Bureau of Standards, Vol. 17

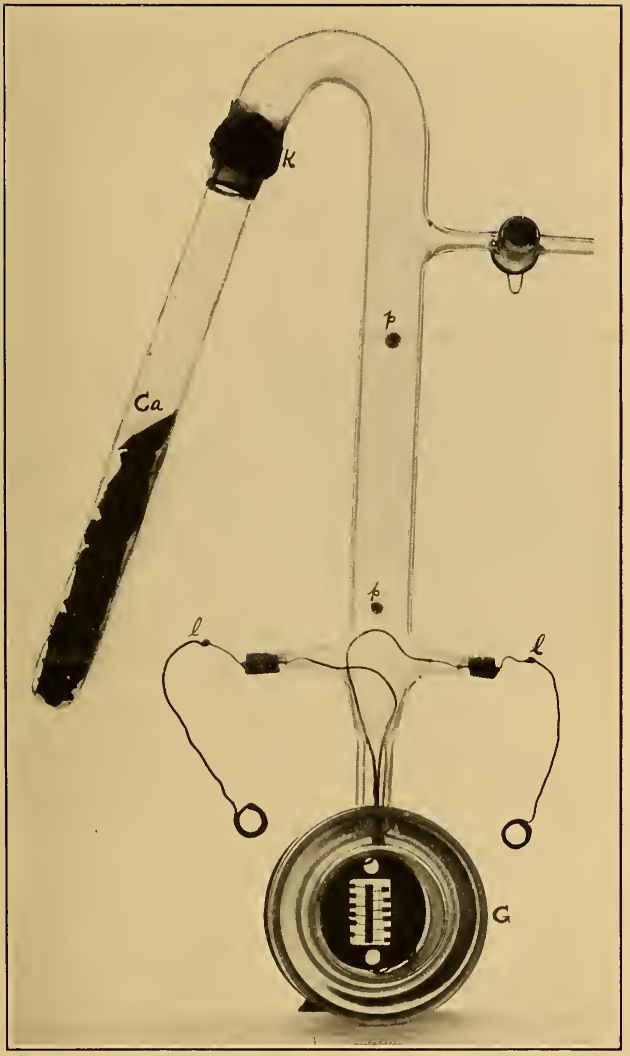

FIG. I.-Vacuum thermopile 
Scientific Papers of the Bureau of Standards, Vol. 17

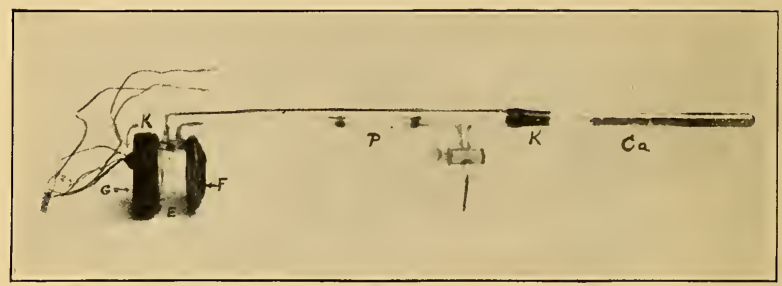

FIG. 2.-Vacuum thermocouple mounting for stellar radiometry 
The linear vacuum thermopile, to be described presently, has been in use for about four years. The first container in which it was mounted always leaked seriously. Nevertheless, after closing the stopcock (in 1917) and sealing it with Chatterton wax, the vacuum was maintained by occasionally heating the calcium.

\section{DESCRIPTION OF THE THERMOPILE}

The thermopile is constructed of bismuth wire, $0.08 \mathrm{~mm}$ in diameter ( $0.1 \mathrm{~mm}$ would be less fragile and hence adapted for general use), and silver wire, $0.03 \mathrm{I} \mathrm{mm}$ in diameter. The individual receivers are of tin, 1.7 by I.I by $0.018 \mathrm{~mm}$. The total length of the receiver of the completed instrument of 12 elements is $12.5 \mathrm{~mm}$, and the resistance is $6.7 \mathrm{ohms}$. The bismuth wire is cut to the proper length $(4 \mathrm{~mm})$ and pressed flat between glass plates to increase thermal conduction where it is in contact with the receivers and thus facilitate the attainment of thermal equilibrium. ${ }^{6}$ The base upon which the thermoelements are mounted may be of ivory or of red fiber (shown in Fig. $\mathrm{r}$ ) which has been boiled in paraffin to shrink it and to expel the air.

The rate of rise of emf of the thermopile, when exposed to radiation, is so rapid that a galvanometer swing of 2 seconds is not retarded. In fact, when using a galvanometer having a single swing of 2 seconds, the response of the thermopile is too rapid for making observations comfortably. For example, 90 per centthat is $18 \mathrm{~cm}$ - of a total deflection of $20 \mathrm{~cm}$ is obtained in about I second.

\section{DESCRIPTION OF THE VACUUM THERMOPILE CONTAINER}

Radiometer containers which can be evacuated have been described in previous papers. ${ }^{7}$

The thermopile in its new vacuum mounting ( $20 \mathrm{~cm}$ in height) is shown in Fig. I, which is a rear view. This mounting is in the form of a cup made out of one piece of glass, which is covered with a thick glass window, $G$. Fig. 2 is a side view of a similar vacuum thermopile container used in stellar radiometry. In these illustrations similar parts are referred to by similar letters. The quartz tube (standard size quartz test tube), containing the calcium, $\mathrm{Ca}$, is attached to the glass tube by means of Khotinsky cement, $K$. Pyrex glass tubing may be used instead of quartz and joined directly to the glass, thus dispensing with the cement, but it is likely to collapse on accidental overheating.

B. S. Bull, 11, pp. 132 and 613 ; 1914.

7 B. S. Bull., 9, p. 39, 1911; 13, p. 444, 1916. 
The electrodes, $p, p$, of platinum wire 0.3 to $0.4 \mathrm{~mm}$ in thickness, are used for testing the evacuation. For this purpose either an induction coil or a 2000 to 10000 volt transformer is used.

The glass window, $G$, covering the rear of the container, is $7 \mathrm{~mm}$ thick. Experience shows that a thick plate of glass is necessary in order to prevent warping by atmospheric pressure and consequent leaking through the ground joint. The latter is closed with a combination of beeswax and tallow (stopcock grease) and the edge is covered with Chatterton wax.

The fluorite window, F, Fig. 2, covering the front of the container, is about $3 \mathrm{~mm}$ in thickness, which is sufficient to prevent warping when placed over the slot ( 8 by $16 \mathrm{~mm}$, Fig. 1 ) in the fine-ground face of the glass receptacle. It is joined to the glass by means of stopcock grease and the outer edge is covered with Chatterton wax.

The lead wires to the thermopile, $l$, Fig. I, are of copper, sealed to the glass with a platinum wire. This refinement is not necessary, though it is desirable to reduce the number of places where leakage may occur.

The glass receptacle is mounted in a brass box which slides in vertical ways as illustrated in previous papers. ${ }^{8}$

In concluding this description of the thermopile container it is relevant to add a few remarks concerning the operation of the calcium evacuator. The calcium is cut into small fragments with a chisel or by other means and placed in the quartz tube, which is then attached to the thermopile container. The device is then evacuated with an oil pump. While the pumping is in progress the calcium is heated with a Bunsen flame in order to cause it to combine with the water vapor, the residual air, and the acetylene gas which is generated from the water vapor and the calcium carbide which is formed in previous use. Keeping the calcium hot, fresh air is allowed to enter and the pumping is continued. This operation should be repeated several times to sweep the water vapor from the walls of the container, after which the stopcock is permanently closed.

With reference to the efficiency of the device, it may be stated that, after the gases have been absorbed by the calcium, the vacuum is so high that the discharge from an induction coil passes through the $5 \mathrm{~cm}$ air space between the electrodes, $p, p$, Fig. I, in preference to passing through the evacuated tube.

B. S. Bull., 11, p 256 , 1914; 13, p. 446, 1916 ("Mounting for vacuum thermopiles"). 
As mentioned elsewhere, an electric heater may be used, but it requires close attention to avoid overheating of the quartz tube. It is not absolutely necessary to use a pump to start the evacuation. However, explosions may result from the increase in pressure of the water vapor, acetylene, etc., when the calcium is first heated in a closed tube at atmospheric pressure. Hence provision must be made for increase in gas pressure during the initial heating of the calcium in a closed tube containing air at atmospheric pressure. For it is to be remembered that the chemical action begins at about $300^{\circ} \mathrm{C}$ and is most effective at a low, red heat.

The first samples of the vacuum chamber with attached calcium evacuator, described in the foregoing pages, were prepared about seven years ago and taken 3200 miles to an observatory without mishap. This experience showed that equipped with several vacuum radiometers of this type one can go to the remotest station without taking a pump.

A further improvement will come from the discovery of a cement for securing the windows which will not give off vapors, and thus increase the efficiency of the device.

\section{CONCERNING RADIATION SENSITIVITY TESTS OF VACUUM RADIOMETERS}

It is beyond the scope of this paper to describe fully the methods of calibration of radiometers and the various methods which may be employed to test the variation in their radiation sensitivity.

In this connection it is to be remembered that the sensitivity of the auxiliary Thomson galvanometer varies with the diumal change in terrestrial magnetism, etc. The current sensitivity may therefore be tested by a simple device described in previous papers. ${ }^{\circ}$

The radiation sensitivity of a vacuum bolometer and to a less extent of a thermopile (because of its greater heat capacity) is a function of the kind and the pressure of the residual gas. The sensitivity of a bolometer is 2.5 as great in hydrogen as in air at the same gas pressure. It has been found by Reinkober ${ }^{10}$ and also by the writer that the radiation sensitivity of the Ruben's thermopile (of wire $0.15 \mathrm{~mm}$ in diameter) in a vacuum is only about 1.5 times that in air. The radiation sensitivity of

'B. S. Bull., 10, p. 19, 1913; 11, p. 17x, 1914, "Specification of the radiation sensitivity of a thermopile."

${ }^{10}$ Reinkober, Ann. der Phys. (4), 34, p. 343; 1911. Lebedew (Ann. der Phys. (4), 9, p. 209; 1902) found that above $s \mathrm{~mm}$ (also below $0.0 \mathrm{~mm}$ ) a variation in gas pressure has but little effect upon the sensitivity. 
the present thermopile is doubled in a vacuum. In this instrument the sensitivity varies but little during the course of a day's work. In making transmissivity (and reflectivity) measurements it is sufficient to have the radiation sensitivity remain constant while making the two sets of measurements, namely, (I) the intensity of the radiation transmitted through the substance, and (2) the intensity of the direct radiation.

If it is desired, the variation in radiation sensitivity of the vacuum thermopile (and of vacuum radiometers in general) may be determined by means of a standard incandescent lamp, ${ }^{11}$ or other suitable means.

In conclusion, it is relevent to empasize the fact that the increase (say, 50 to roo per cent) in radiation sensitivity by placing the ordinary laboratory radiometer (thermopile) in a vacuum is relatively small, and that the chief gain lies in elimination of unsteadiness of the galvanometer reading by elimination of convection currents. -This is easily accomplished by keeping the air pressure less than $0.1 \mathrm{~mm}$.

WASHINGTON, March 4, I921.

11 McCauley, Astrophys, J., 37, p. 164; 1913. 